\title{
Metabolism of $\alpha$-Methyltyrosine in Man:
}

\section{Relationship to Its Potency as an \\ Inhibitor of Catecholamine Biosynthesis}

\author{
Karl Engelman, Eric Jéquier, Sidney Udenfriend, and Albert Sjoerdsma \\ From the Experimental Therapeutics Branch and Laboratory of Clinical \\ Biochemistry, National Heart Institute, Bethesda, Maryland
}

A в S TRACT The metabolic fate of the tyrosine hydroxylase inhibitor, $\alpha$-methyl-para-tyrosine $(\alpha-\mathrm{MPT})$, was studied after oral administration of single and multiple doses to patients with pheochromocytoma and essential hypertension. No major urinary excretion product was found other than the drug itself, which accounted for $44-88 \%$ of the fate of single or repeated oral doses. Though less than $1 \%$ of the administered drug could be recovered in the urine as catechol metabolites, it was possible to identify $\alpha$-methyldopa, $\alpha$-methyldopamine, and $\alpha$-methylnorepinephrine and to quantify the excretion of the first two of these compounds. This minor route of metabolism required revision of methodology (presented herein) for measuring urinary catecholamines during $\alpha$-MPT treatment since these compounds produce spurious fluorescence in routine methods of assay for catecholamines. The catechol metabolites probably are not present in sufficient amounts to contribute to the biochemical effects of the drug. Determination of plasma concentrations of $\alpha$-MPT during maintenance therapy and considerations of the kinetics of enzyme inhibition enabled a calculation to be made of the degree of inhibition of catecholamine synthesis to be expected in the patient. This was calculated to be about $75 \%$ for the highest doses employed and is similar in magnitude to experimentally determined values.

Received for publication 9. August 1967.

\section{INTRODUCTION}

Alpha methyltyrosine ( $\alpha$-methyl-para-tyrosine, $\alpha$-MPT) is an inhibitor of the first and ratelimiting reaction in catecholamine biosynthesis, the hydroxylation of tyrosine to form 3,4-dihydroxyphenylalanine (dopa). Studies in our laboratories have shown the drug to block catecholamine biosynthesis and thereby deplete tissue catecholamines in laboratory animals $(1,2)$. A similar inhibitory effect was also shown in man, as judged from the finding that daily doses of $\alpha$-MPT of $600-4000 \mathrm{mg}$ produce a $23-70 \%$ decrease in the urinary excretion of catecholamine metabolites $(3,4)$.

In the present work, we identified and quantified urinary products of the drug after oral dosing. Some of the methodology employed permits estimation of naturally occurring urinary catecholamines in the presence of catechol metabolites of the drug. Measurements of plasma levels of drug form the basis for a comparison of predicted vs. indirectly measured inhibition of tyrosine hydroxylase in man. A companion paper (5) will deal in more detail with the altered catecholamine metabolism and pharmacological effects produced by $\alpha$-MPT in human subjects.

\section{METHODS}

All studies were conducted on hospitalized patients. The fate of single oral doses of $\alpha$-MPT was studied in three adult patients without gastrointestinal or renal disease. Urinary metabolites of the drug were also studied in 22 
patients with pheochromocytoma and 12 patients with uncomplicated essential hypertension while they were receiving maintenance therapy. Clinical data on these patients are given in the accompanying paper (5).

Nonradioactive and radioactive $\alpha$-MPT $\left({ }^{3} \mathrm{H}\right.$, uniformly labeled, $72.2 \mu \mathrm{c} / \mathrm{mg}$ ) were supplied as the levo-isomeric free acid. ${ }^{1}$ In studies on the fate of single doses, both forms of the compound were mixed in a vehicle of apple sauce and administered to fasting patients. Maintenence doses of the drug were administered orally in capsules, three to four times per day. Timed urine collections were obtained in glass bottles containing sufficient $6 \mathrm{~N} \mathrm{HCl}$ to yield a final sample $\mathrm{pH}$ less than 2.0, which permitted prolonged storage at $0-4^{\circ} \mathrm{C}$. Blood samples were collected in heparinized syringes and the plasma separated and frozen until assay.

\section{Chemical assays}

(a) $\alpha$-Methyltyrosine. $\alpha$-MPT was assayed by a modification of the fluorescence assay for tyrosine (6). An aliquot of urine generally equivalent to $0.01 \%$ of the $24-\mathrm{hr}$ excretory volume was diluted to $30 \mathrm{ml}$ with water and $1.0 \mathrm{ml}$ was reacted with the nitroso-naphthol reagent. Urine collected during control periods was assayed similarly; the small values obtained (less than $100 \mathrm{mg} / 24 \mathrm{hr}$ ) were used to correct the experimental values for fluorescence attributable to urinary tyrosine. Several specimens were assayed for $\alpha$-MPT before and after hydrolysis. We performed acid hydrolysis by adjusting the urine sample to $\mathrm{pH} 1$ with $1.0 \mathrm{~N} \mathrm{HCl}$ and heating at $100^{\circ} \mathrm{C}$ for $1 \mathrm{hr}$. Enzymatic hydrolysis was achieved on $10-\mathrm{ml}$ aliquots of urine which were first adjusted to $\mathrm{pH} 11$ with $2.5 \mathrm{~N} \mathrm{NaOH}$ followed by the addition of $0.4 \mathrm{ml}$ of saturated $\mathrm{BaCl}_{2}$ to precipitate inorganic phosphates and sulfates. After centrifugation the supernatant was adjusted to $\mathrm{pH} 4.5$ with $1 \mathrm{~N} \mathrm{HCl}$ and incubated for $24 \mathrm{hr}$ at $37^{\circ} \mathrm{C}$ with $0.2 \mathrm{ml}$ of $\beta$-glucuronidase and sulfatase (Glusulase $^{2}$ contained $\beta$-glucuronidase, $100,000 \mathrm{U} / \mathrm{ml}$, and sulfatase, $50,000 \mathrm{U} / \mathrm{ml}$ ). $50-100 \mu \mathrm{g}$ of $\alpha$-MPT carried through the procedure was recovered satisfactorily $(95 \pm 5 \%)$.

Plasma concentrations of $\alpha$-MPT were determined in the three patients who received single doses of $1000 \mathrm{mg}$ of $\alpha$-MPT with $\alpha$-MPT $-{ }^{3} \mathrm{H}$. To $1.0 \mathrm{ml}$ plasma was added $1.0 \mathrm{ml}$ of water and $0.5 \mathrm{ml}$ of $40 \%$ trichloroacetic acid. After centrifugation at $4^{\circ} \mathrm{C}$ to separate the protein precipitate, we measured the radioactivity in the supernatant in a scintillation spectrometer. Plasma concentrations of $\alpha$-MPT could be calculated from the radioactivity of the plasma sample and the specific activity of the administered. $\alpha$-MPT. Plasma concentrations of $\alpha$-MPT were also determined fluorometrically $(6)$ in two patients receiving $500 \mathrm{mg}$ of $\alpha-\mathrm{MPT}$ at 6 -hr intervals. Since the fluorometric method does not distinguish tyrosine from $\alpha$-MPT, we obtained fasting plasma samples before treatment and subtracted the control values from those

\footnotetext{
1 Supplied by Dr. Elmer Alpert, Merck \& Co., West Point, $\mathrm{Pa}$.

2 Endo Laboratories, Inc. Richmond Hill, New York.
}

during treatment. Blood samples during treatment were drawn in the fasting state $3 \mathrm{hr}$ after a dose of drug.

(b) $\alpha$-Methyltyramine. Assay of $\alpha$-methyltyramine in urine was accomplished after separation from $\alpha$-MPT on a cationic exchange resin (Amberlite IRC-50, 100-200 mesh, $\mathrm{Na}^{+}$form, buffered at $\mathrm{pH} 6.5$ with $1 \mathrm{M}$ acetate buffer). After adjustment to $\mathrm{pH} 6.0$ with $1 \mathrm{~N} \mathrm{NaOH}$, a $20 \mathrm{ml}$ urine sample was passed over a $1.2 \times 4.5 \mathrm{~cm}$ column of the resin. The column was washed with $75 \mathrm{ml}$ of $\mathrm{H}_{2} \mathrm{O}$ and the $\alpha$-methyltyramine eluted with $30 \mathrm{ml}$ of $1 \mathrm{~N}$ acetic acid. A $2 \mathrm{ml}$ aliquot of the eluate was assayed for $\alpha$-methyltyramine by the nitroso-naphthol reaction as for $\alpha$-MPT. Internal standards of $5 \mu \mathrm{g}$ of $\alpha$-methyltyramine were added to a duplicate of each urine sample; recoveries of $\alpha$-methyltyramine through the procedure were $90 \pm 10 \%$. Urine obtained during a control period served to correct experimental values for fluorescence due to urinary tyramine. Addition of as much as $1000 \mu \mathrm{g}$ of $\alpha$-MPT to samples carried through the procedure failed to increase apparent $\alpha$-methyltyramine values indicating that parent drug in the urine would not interfere with the amine assay.

(c) Norepinephrine, $\alpha-m e t h y l d o p a$, and $\alpha$-methyldopamine. During the control periods, urinary catecholamines (epinephrine plus norepinephrine as norepinephrine equivalents) were assayed after adsorption and elution from an alumina column (7) and oxidation by potassium ferricyanide to fluorescent trihydroxyindoles (8). When the patients were receiving $\alpha$-MPT two additional column chromatographic steps were required to separate urinary catechol metabolites of the drug from the normal catecholamines. After adsorption of the catechol compounds on alumina, the column was eluted with $15 \mathrm{ml}$ of $0.2 \mathrm{~N}$ acetic acid. The eluate was adjusted to $\mathrm{pH} \quad 6.0-6.2$ and catecholamines were then separated from catechol acids and neutral compounds by application to a $7 \times 135 \mathrm{~mm}$ Amberlite IRC-50 column. The column was washed with $5 \mathrm{ml}$ of water and both the effluent and wash were collected for assay of $\alpha$-methyl-3,4-dihydroxyphenylalanine ( $\alpha$-methyldopa). The column was then washed with an additional $25 \mathrm{ml}$ of water, and elution was performed with $15 \mathrm{ml}$ of $1.0 \mathrm{~N}$ acetic or hydrochloric acid. The eluate containing the catecholamines was adjusted to $\mathrm{pH} 4.0$ with $1 \mathrm{~N} \mathrm{NaOH}$ and passed over a $7 \times 60 \mathrm{~mm}$ Dowex-50 column (100-200 mesh, $\mathrm{Na}^{+}$form, buffered with $1 \mathrm{~N}$ acetate buffer, $\mathrm{pH} 6.5$ ); the column was washed with 20 $\mathrm{ml}$ of water and $12.5 \mathrm{ml}$ of $0.4 \mathrm{~N} \mathrm{HCl} .35 \mathrm{ml}$ of $0.4 \mathrm{~N} \mathrm{HCl}$ were then added to elute norepinephrine and epinephrine followed by $30 \mathrm{ml}$ of $2.0 \mathrm{~N} \mathrm{HCl}$ to obtain $\alpha$-methyl-3,4dihydroxyphenylethylamine ( $\alpha$-methyldopamine) and dopamine. After adjustment of $\mathrm{pH}$ to $6.0-6.5$, the various catechol fractions, along with appropriate standards, were oxidized by minor modifications of the ferricyanide method to fluorescent trihydroxyindoles and fluorescence determined in a fluorescence spectrometer ${ }^{3}$ at an excitation wave length of $395 \mathrm{~m} \mu$ and a fluorescence wave length of $515 \mathrm{~m} \mu$ (uncorrected). Under conditions of the assays fluorescence contributed by urinary dopa and dopamine was insignificant.

\footnotetext{
3 American Instrument Co., Silver Spring, Md.
} 
We determined recoveries through the column steps involved in these assays by adding tracer amounts of norepinephrine- $7-{ }^{3} \mathrm{H}$ or epinephrine- $2{ }^{14} \mathrm{C}$ to each sample before adsorption on the alumina column. Recoveries of the labeled tracer compounds 4 in the final catechol fractions were determined by scintillation counting (see below). Recoveries through the single alumina column averaged $74 \%$ and through all three column steps averaged $60 \%$; the results for each sample were corrected for the recovery of a radioactive tracer run as an internal standard. Separate studies with standard solutions of all the compounds in question demonstrated that little error was involved in applying this same tracer method to correct for recovery of the other catechol compounds.

\section{Chromatographic identification of urinary metabolites}

Paper chromatographic separation of compounds was performed on: (a) No. 1 Whatman paper with the solvent systems $n$-butanol : acetic acid: water $(12: 3: 5)$ or phenol: ammonia $(1: 200), 20 \mathrm{hr}$, descending; and $(b)$ cellulose phosphate cation-exchange paper (No. P-81 Whatman) with solvent system composed of 2 parts $0.2 \mathrm{~m}$ ammonium acetate adjusted to $\mathrm{pH} 6.0$ with $1 \mathrm{~N}$ acetic acid and 1 part isopropanol, $16 \mathrm{hr}$, descending (9). Samples were chromatographed separately and in cochromatography with appropriate authentic standards. We located catechol compounds by spraying with Gibbs' reagent (2, 6-dichlorobenzoquinone- $4-N$-chloro-imine, $0.05 \%$ in absolute alcohol). We localized $\alpha$-MPT by dipping the paper in $0.2 \%$ ninhydrin in acetone followed by heating at $100^{\circ} \mathrm{C}$ for $30 \mathrm{~min}$.

(a) $\alpha$-Methyltyrosine. Samples, $0.25 \mathrm{ml}$, of urine from a patient who had received $1000 \mathrm{mg}$ of $\alpha$-MPT and 1093 $\mu \mathrm{c}$ of $\alpha-\mathrm{MPT}-{ }^{3} \mathrm{H}$ in a combined oral dose were chromatographed in both solvent systems on No. 1 Whatman paper. Chromatograms were dipped in ninhydrin reagent, and paper strips were scanned for localization of radioactivity.

(b) $\alpha$-Methyldopa. Urine from the same study, collected during the first $24 \mathrm{hr}$ after administration of drug, was divided into 10 aliquots and applied successively to alumina and IRC-50 columns as described above. Effluent and wash fractions from IRC-50 columns were combined, lyophilized, resuspended in a small volume of $0.01 \mathrm{~N} \mathrm{HCl}$, and chromatographed on cellulose phosphate paper for subsequent spraying and strip counting. The IRC-50 eluates were used to identify $\alpha$-methyldopamine and $\alpha$-methylnorepinephrine (see below).

Similar procedures were utilized in an isotope dilution experiment carried out on urine from a patient with essential hypertension, who received $2000 \mathrm{mg}$ of $\alpha$-MPT daily. Tracer amounts of $\alpha$-methyldopa- $2-{ }^{14} \mathrm{C}, 5.2 \mu \mathrm{c} / \mathrm{mg},{ }^{5}$ were added to four $20 \%$ aliquots of a $24 \mathrm{hr}$ urine sample before column chromatography. The IRC-50 column

\footnotetext{
4 Obtained from New England Nuclear Corporation, Boston, Mass.

5 Supplied by Dr. Karl Pfister, Merck \& Co., Rahway, N. J.
}

effluents were reapplied to alumina, and the second alumina eluates were reduced to a small volume in vacuo for paper chromatography on No. 1 Whatman paper. Aliquots of the IRC-50 effluent, second alumina eluate, and a spot on paper which had the same $R_{f}$ as authentic $\alpha$-methyldopa were assayed for radioactivity and catecholamine fluorescence to determine specific activity.

(c) $\alpha$-Methyldopamine and $\alpha$-methylnorepinephrine. These compounds were identified in the IRC-50 eluates obtained as described above in the study of the patient who received a combined dose of labeled and unlabeled $\alpha$-MPT. Pooled IRC-50 eluates were applied to an alumina column, the acetic acid eluate was evaporated to dryness in vacuo, mixed in a small volume of $0.01 \mathrm{~N}$ $\mathrm{HCl}$, and applied to cellulose phosphate paper. The paper strips were scanned for radioactivity and spots corresponding to the authentic compounds (cochromatographed) were then cut out, eluted with $1.5 \mathrm{ml}$ of $0.01 \mathrm{~N}$ $\mathrm{HCl}$, and radioactivity measured in a scintillation spectrometer.

Strip counting of chromatograms was performed on an automatic chromatogram scanner ${ }^{6}$ with a $4 \pi$-ionization detector. No attempt was made to determine the efficiency of such counting, and it was used solely for qualitative purposes. Radioactivity in aqueous samples was determined as described by Bray (10) in a liquid scintillation spectrometer. ${ }^{7}$ We determined counting efficiency and calculation of the absolute radioactivity of each sample in dpm by referring to experimentally derived quench curves for the automatic external standardization (AES) device. All counting was done to at least $95 \%$ confidence limits.

\section{RESULTS}

\section{Identification of urinary products}

(a) $\alpha$-Methyltyrosine. Paper chromatography in two solvent systems of an aliquot of untreated urine from a patient receiving a combined dose of labeled and unlabeled $\alpha$-MPT revealed a single radioactive spot with the same $R_{f}$ and staining characteristics as authentic $\alpha$-MPT. One of these chromatograms is depicted in Fig. 1. Since no other radioactive peak was found by these procedures, it was concluded that there was no major urinary excretion product of $\alpha$-MPT other than the drug itself. The small amounts of other metabolites which were present required isolation and concentration before detection.

(b) Catechol compounds. $\alpha$-Methyldopa was identified in the urine of patients who received the combined dose of labeled and unlabeled $\alpha$-MPT

\footnotetext{
6 Vanguard Autoscanner 880, Technical Measurement Corp., North Haven, Conn.

${ }^{7}$ Model 4000, Packard Instrument Co., Downers Grove, Ill.
} 


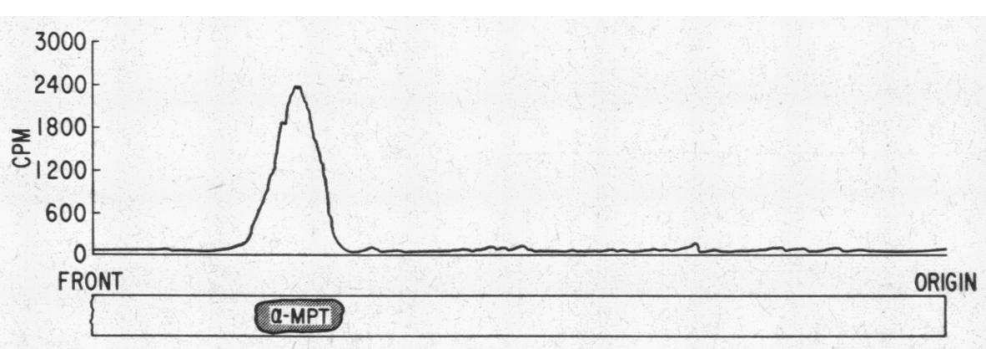

FIgURE 1 Identification of $\alpha$-MPT in urine. This is a semischematic presentation of results obtained when $250 \mu \mathrm{l}$ of urine from a patient receiving a combined dose of $\alpha-\mathrm{MPT}$ and $\alpha-\mathrm{MPT}-{ }^{8} \mathrm{H}$ was chromatographed in a phenol-ammonia system on No. 1 Whatman paper, stained with ninhydrin and strip-counted for localization of radioactivity. The single radioactive peak in the upper portion (full scale deflection $=3000 \mathrm{cpm}$ ) was found to coincide with the localization of cochromatographed $\alpha$-MPT.

as well as in the urine of patients on maintenance treatment. Chromatography of the catechol acid fraction of urine from a patient who had received $\alpha-\mathrm{MPT}-{ }^{3} \mathrm{H}$ revealed a single radioactive peak corresponding in $R_{f}$ to that of authentic $\alpha$-methyldopa (Fig. 2). Similarly, we identified unlabeled $\alpha$-methyldopa in the urine of a patient receiving maintenance doses of $\alpha$-MPT, using $\alpha$-methyldopa$2-{ }^{14} \mathrm{C}$ as a tracer, and a combination of column and paper chromatography. We chromatographed aliquots of the final alumina column fraction, and found a single spot corresponding in its $R_{f}$ to authentic $\alpha$-methyldopa both by strip counting and spraying with Gibbs' reagent. An unstained portion of the paper corresponding to another aliquot chromatographed in parallel was cut into four segments, eluted, and the specific activity of the apparent $\alpha$-methyldopa was determined. Comparison of this material with that obtained in the previous purification steps revealed relative constancy of specific activity (Table I), confirming identification of the compound as $\alpha$-methyldopa and indicating that it could be assayed reliably in the IRC-50 effluent.

The identification of $\alpha$-methyldopamine and $\alpha$-methylnorepinephrine in urine from patients receiving $\alpha$-MPT $-{ }^{3} \mathrm{H}$ rested on the demonstration of significant radioactivity on the chromatograms in areas corresponding to authentic compounds which were chromatographed with the isolated material. Though the amount of radioactive label on the chromatogram was insufficient to give localization by strip scanning, measurable amounts of tritium-labeled material were found when the spots were eluted and counted by the much more sensitive scintillation counting procedure. Spots corresponding to $\alpha$-methyldopamine- ${ }^{3} \mathrm{H}$ and $\alpha$-methylnorepinephrine- ${ }^{3} \mathrm{H}$ had net radioactivity

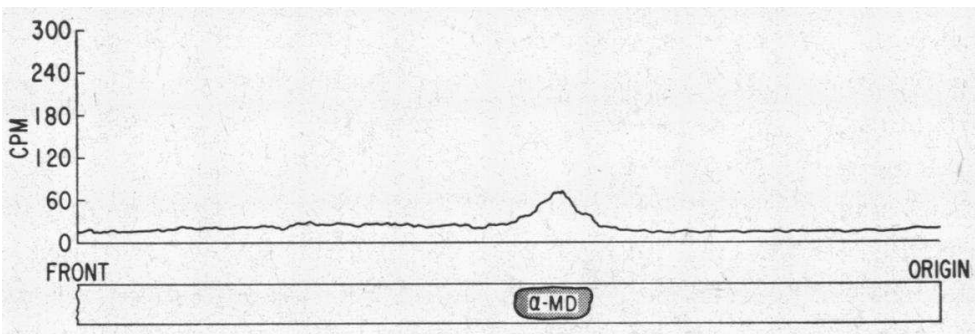

FIGURE 2 Identification of $\alpha$-methyldopa in urine. Results are shown of chromatography on cellulose phosphate cation-exchange paper of a portion of the catechol acid fraction of urine from a patient receiving a combined dose of $\alpha$-MPT ${ }^{8} \mathrm{H}$ and $\alpha$-MPT. Localization of the cochromatographed authentic $\alpha$-methyldopa with the radioactive peak revealed identical $R_{f}$ values for the two materials. Full scale deflection for radioactivity on this chromatogram was $300 \mathrm{cpm}$. 
TABLE I

Isotope Dilution Study for the Identification of $\alpha$-Methyldopa*

\begin{tabular}{lccc}
\hline \multicolumn{1}{c}{ Assay fraction } & & $\begin{array}{c}\text { Apparent } \\
\alpha \text {-methyl- } \\
\text { dopa }\end{array}$ & $\begin{array}{c}\text { Specific } \\
\text { activity }\end{array}$ \\
\hline IRC-50 effluent & $d p m$ & $\mu g$ & $d p m / \mu g$ \\
Second alumina eluate & 605,000 & 696 & 868 \\
Paper chromatography & 159,000 & 403 & 963 \\
\hline
\end{tabular}

* See text for details.

equal to 320 and $280 \mathrm{dpm}$, respectively, as compared to $16 \mathrm{dpm}$ above background for blank portions of the same strip adjacent to these spots.

\section{Studies on the absorption and excretion of drug}

(a) Single dose studies. The cumulative urinary excretion of radioactivity and unlabeled drug after simultaneous ingestion of $1000 \mathrm{mg}$ of $\alpha$-MPT and tracer $(1.08-1.09 \mathrm{mc}) \alpha-\mathrm{MPT}^{-3} \mathrm{H}$ in three patients is shown in Fig. 3. Total excretion as unchanged drug in these subjects ranged from $45-88 \%$ of the administered oral dose. The very close agreement of per cent excretion of unchanged drug and total radioactivity is to be noted and demonstrates again that there is no major biotransformation of the drug. These findings are in accord with the demonstration of a single radioactive spot on chromatography of untreated urine (see above). Any differences that exist between the percentages of total administered drug and radioactivity excreted are compatible with the inherent errors of the methods employed for chemical analysis and counting of radioactivity. Excretion of the drug was fairly rapid with 50 $60 \%$ of the total amount excreted appearing in the urine during the first $8 \mathrm{hr}$ and $80-90 \%$ in the first $24 \mathrm{hr}$. Small amounts of the drug still were found in the urine during the 3rd day.

Plasma concentrations of the drug were determined during the same studies in these three subjects. As described in the section on Methods the values for plasma concentrations in these cases were calculated from the levels of total plasma radioactivity and the specific activity of the administered $\alpha$-MPT dose. This indirect assay seemed permissible since the drug undergoes only slight conversion to other metabolites. Peak plasma concentrations of $12-14 \mu \mathrm{g}$ of $\alpha-\mathrm{MPT} / \mathrm{ml}$ of

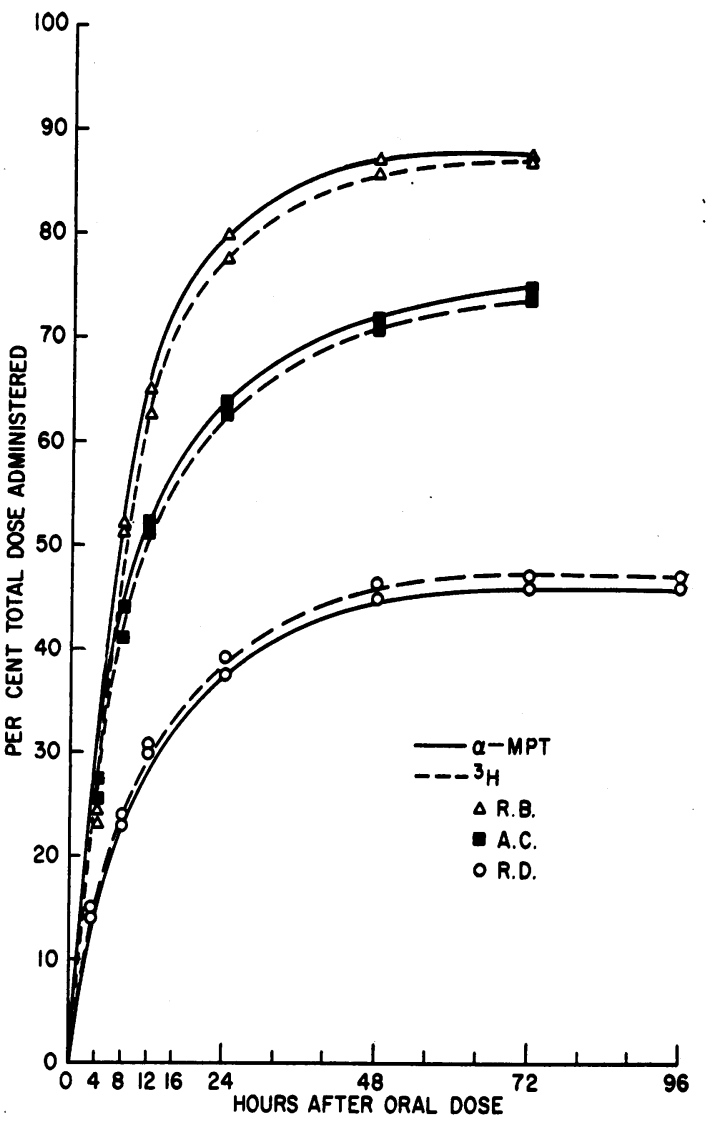

FIGURE 3 Cumulative urinary excretion of radioactivity and unchanged drug after ingestion of a combined dose of $\alpha$-MPT $-{ }^{3} \mathrm{H}$ and $\alpha$-MPT (1.0 g) by three patients.

plasma were achieved between 1 and $3 \mathrm{hr}$ after ingestion (Fig. 4). When the values of plasma concentrations during $\mathrm{hr} 2-8$ were plotted on semilog paper the drug appeared to have a plasma half-life of $3.4,3.5$, and $3.7 \mathrm{hr}$ in these three subjects. Traces of radioactivity were still present in blood collected $24 \mathrm{hr}$ after the dose was administered.

(b) Maintenance dose studies. The data in Table II represent results of urinary assays in 34 patients during treatment with maximal doses of drug. The intestinal absorption of $\alpha$-MPT as measured by its urinary excretion was $53-88 \%$ of the administered dose with a mean of $69 \%$. Similar values were obtained for patients with pheochromocytoma and those with essential hypertension. Studies in 13 of the patients during stepwise increases in maintenance dosage indicated that absorption of the drug was essentially the 


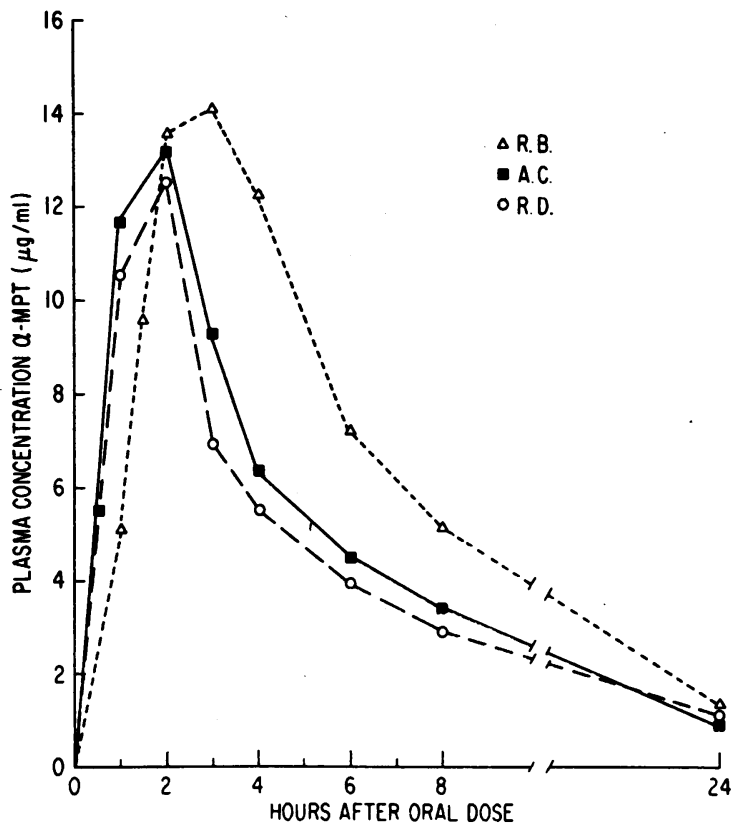

Figure 4 Plasma levels of $\alpha$-MPT in three subjects after ingestion of $1.0 \mathrm{~g} \alpha$-MPT combined with a tracer dose of $\alpha$-MPT $-{ }^{3} \mathrm{H}$. The values were calculated from experimentally determined radioactivity of plasma and the specific activity of the administered $\alpha$-MPT dose. Plotting data for hr 2-8 on semilog paper indicated apparent plasma half-lives of $\alpha$-MPT of approximately $31 / 2 \mathrm{hr}$.

same in a given individual over a dose range from 300 to $4000 \mathrm{mg} /$ day. Treatment of urine samples by acid or enzymatic hydrolysis resulted in no increment of assayable $\alpha$-MPT, which indicated that the drug is not excreted in a conjugated form.

Fasting plasma concentrations of $\alpha$-MPT determined fluorometrically in two patients during maintenance therapy with $500 \mathrm{mg} \alpha$-MPT every $6 \mathrm{hr}$ revealed average levels of 13.5 and $14.0 \mu \mathrm{g} / \mathrm{ml}$ respectively, $3 \mathrm{hr}$ after the daily 6 a.m. dose of drug. The fasting tyrosine levels in the same patients were 9.5 and $13.0 \mu \mathrm{g} / \mathrm{ml}$ during control periods.

\section{Excretion of drug metabolites}

Urinary excretion of $\alpha$-methyldopa during maintenance therapy was studied in 21 patients with pheochromocytoma (Table II). Although $\alpha$-methyldopa was excreted in only milligram quantities, it was the major metabolite of the drug which we detected. In these patients, the amount of $\alpha$-methyldopa excreted was only $0.1-0.4 \%$ of
TABLE II

Urinary Excretion of $\alpha$-Methyltyrosine and Its Catechol Metabolites during Maintenance Therapy

\begin{tabular}{|c|c|c|c|c|c|}
\hline \multirow[b]{2}{*}{ Patient } & \multirow[b]{2}{*}{ Oral dose } & \multicolumn{4}{|c|}{ Urinary excretion } \\
\hline & & $\alpha-\mathrm{MPT}$ & $\alpha-M D$ & $\alpha-\mathrm{MDA}$ & $\begin{array}{l}\% \text { of } \\
\text { Dose* }\end{array}$ \\
\hline Pheochromc & $\begin{array}{l}\mathrm{mg} / 24 \mathrm{hr} \\
\text { cytoma }\end{array}$ & \multicolumn{4}{|c|}{$m g / 24 h r$} \\
\hline E. D. & 600 & 475 & 2.0 & 0.37 & 79 \\
\hline C. B. & 1200 & 1050 & 3.4 & 0.38 & 88 \\
\hline W. L. & 2000 & 1230 & 6.4 & 0.11 & 62 \\
\hline D. B. & 2000 & 1320 & 5.2 & 0.83 & 66 \\
\hline D. K. & 2000 & 1060 & 3.8 & 0.68 & 53 \\
\hline E. L. H. & 2500 & 1975 & 4.4 & 0.87 & 79 \\
\hline K. K. & 3000 & 2000 & 2.3 & 0.26 & 67 \\
\hline E. D. & 2500 & 1510 & 2.6 & 0.10 & 60 \\
\hline E. A. & 2000 & 1500 & 6.7 & 1.15 & 75 \\
\hline D. L. & 3500 & 2235 & 5.3 & 0.37 & 64 \\
\hline K. L. & 3000 & 2170 & 8.1 & 1.91 & 72 \\
\hline S. K. & 1500 & 890 & & & 59 \\
\hline B. B. & 3500 & 2350 & 4.5 & 1.43 & 67 \\
\hline S. M. & 4000 & 2800 & 10.4 & 0.72 & 70 \\
\hline E. H. & 2000 & 1420 & 5.4 & 0.59 & 71 \\
\hline T. W. & 1500 & 1050 & 6.5 & 1.32 & 70 \\
\hline E. W. & 4000 & 2900 & 16.9 & 0.93 & 73 \\
\hline R. K. & 2000 & 1700 & 4.3 & 0.11 & 85 \\
\hline J. D. & 2500 & 1490 & 3.3 & 0.15 & 60 \\
\hline A. A. & 3500 & 2100 & 7.7 & 1.15 & 60 \\
\hline J. L. & 2000 & 1250 & 3.2 & 0.10 & 63 \\
\hline F. M. & 3500 & 1855 & 11.4 & 2.30 & 53 \\
\hline
\end{tabular}

Essential hypertension

$\begin{array}{lrrr}\text { A. N. } & 800 & 650 & 81 \\ \text { G. E. } & 3000 & 2170 & 72 \\ \text { E. H. } & 3000 & 2140 & 71 \\ \text { A. M. } & 3000 & 1945 & 65 \\ \text { G. D. } & 2000 & 1580 & 79 \\ \text { D. E. } & 2000 & 1175 & 59 \\ \text { D. F. } & 1200 & 890 & 74 \\ \text { S. C. } & 1600 & 1000 & 63 \\ \text { V. G. } & 800 & 600 & 75 \\ \text { F. B. } & 1600 & 1050 & 66 \\ \text { E. B. } & 2250 & 1480 & 66 \\ \text { F. D. } & 800 & 670 & 84\end{array}$

$\alpha$-MPT, $\alpha$-methyltyrosine; $\alpha$-MD, $\alpha$-methyldopa ; $\alpha$-MDA, $\alpha$-methyldopamine.

* Of the values shown $\alpha$-methyldopa represents only $0.1-0.4 \%$ and $\alpha$-methyldopamine $0.004-0.09 \%$.

the oral dose of $\alpha$-MPT. After ingestion of a single combined dose of labeled and unlabeled $\alpha$-MPT, $\alpha$-methyldopa- ${ }^{3} \mathrm{H}$ was assayed in a patient's urine. The material was counted after chromatography and elution from the paper, and with estimates of the recovery of the labeled material through the various column and paper chro- 
matographic steps it was determined that only about $0.001 \%$ of the administered single dose of $\alpha$-MPT $-{ }^{3} \mathrm{H}$ was excreted as $\alpha$-methyldopa $-{ }^{3} \mathrm{H}$ during the first $24 \mathrm{hr}$. This suggests that a significant accumulation of $\alpha$-methyldopa occurs during repeated dosing with drug.

Assays of $\alpha$-methyldopamine in urine samples from patients with pheochromocytoma during maintenance therapy with $\alpha$-MPT revealed a range of $0.1-1.91 \mathrm{mg} / 24 \mathrm{hr}$ (Table II), which represented only $0.004-0.09 \%$ of the oral dose of $\alpha$-MPT. $\alpha$-Methylnorepinephrine could not be measured in the urine from patients receiving maintenance therapy with $\alpha$-MPT because column chromatography did not separate this compound from epinephrine and norepinephrine. It was possible, however, to get an estimate of $\alpha$-norepinephrine- ${ }^{3} \mathrm{H}$ excretion after ingestion of $\alpha-\mathrm{MPT}-{ }^{3} \mathrm{H}$ by the same procedure as for the estimation of $\alpha$-methyldopamine- ${ }^{3} \mathrm{H}$ excretion. It was found that $\alpha$-methylnorepinephrine- ${ }^{3} \mathrm{H}$ excretion accounted for only $0.0005-0.0001 \%$ of the oral dose.

Small amounts of apparent $\alpha$-methyltyramine were found in the urine. In two patients receiving $\alpha$-MPT $-{ }^{3} \mathrm{H}, 0.005$ and $0.014 \%$ of the administered dose was recovered as apparent $\alpha$-methyltyramine. In four patients on maintenance treatment, from 0.026 to $0.037 \%$ of ingested $\alpha$-MPT appeared as $\alpha$-methyltyramine in the urine. These are maximal values and could include small amounts of other amine products.

\section{DISCUSSION}

A thorough knowledge of the fate of oral doses of $\alpha$-MPT in man was considered important for at least three reasons. First, a definitive explanation was needed for spurious urinary fluorescence previously observed during treatment with $\alpha$-MPT, which interfered with accurate assay of the normal urinary catecholamines $(3,4)$. Second, the question exists whether biochemical and pharmacological effects produced by $\alpha$-MPT are due to actions of the drug itself, or to metabolic products. Third, it was necessary to know whether $\alpha$-MPT was sufficiently well absorbed to warrant extensive clinical trials and whether the blood levels obtained were sufficient to account for the reduction in catecholamine biosynthesis.

Though the major urinary excretory product was $\alpha$-MPT itself, evidence was obtained of a minor degree $(<1 \%)$ of decarboxylation to $\alpha$-methyltyramine. A similarly minor pathway of metabolism to $\alpha$-methyldopa, $\alpha$-methyldopamine, and $\alpha$-methylnorepinephrine was defined unequivocally (Fig. 5). The milligram quantities of these latter compounds excreted during maintenance therapy with $\alpha$-MPT are sufficient, however, to increase "apparent" catecholamine values determined by routine techniques. This interference is more evident in patients with essential hypertension with normal urinary catecholamine excretion $(<100 \mu \mathrm{g} / 24 \mathrm{hr})$ than in patients with pheochromocytoma whose values are usually $10-100$ times normal. Nevertheless, accurate assay of urinary catecholamines in the presence of drug even in patients with pheochromocytoma required a modified assay, the results of which will be presented in the accompanying report (5). No attempt was made to isolate $O$-methylated metabolites of the catechol drug products though these presumably would also be present.

It was concluded from experiments in animals<smiles>CC(N)(Cc1ccc(O)cc1)C(=O)O</smiles>

alpha methyl-para-tyrosine ( $\alpha$-MPT)<smiles>CC(N)(Cc1ccc(O)c(O)c1)C(=O)O</smiles>

alpha methyl-dopa ( $Q-M D)$<smiles>CC(N)Cc1ccc(O)c(O)c1</smiles>

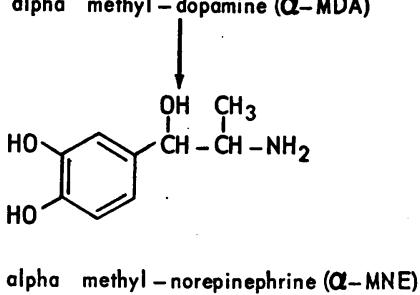

Figure 5 A minor $(<1 \%)$ pathway of $\alpha$-MPT metabolism, which proceeds by the same enzymatic steps by which norepinephrine is synthesized from tyrosine. 
that inhibition of tyrosine hydroxylase is directly responsible for the depletion of tissue levels of norepinephrine produced by single doses of the drug $(1,2)$. Decarboxylation of $\alpha$-MPT to $\alpha$-methyltyramine was not detected (1); the present findings of only minimal over-all conversion to $\alpha$-methyltyramine in urine are in agreement. Though radioactive $\alpha$-methylnorepinephrine has been found in animal tissues after administration of $\alpha-\mathrm{MPT}-{ }^{3} \mathrm{H}$ changes in tissue norepinephrine correlate with the inhibition of the conversion of tyrosine to dopa produced by $\alpha$-MPT rather than with the appearance in tissues of catecholamine products of the drug (2). Again, the clinical studies are in agreement, at least with respect to any role of catechol drug products in decreasing catecholamine biosynthesis. Actually, even in therapeutic doses $\alpha$-methyldopa does not appreciably alter catecholamine synthesis in man (11).

However, since the pharmacological effects of $\alpha$-methyldopa are thought to be mediated through its amine metabolites, $\alpha$-methyldopamine and $\alpha$-methylnorepinephrine, which may act in part as false sympathetic neurotransmitters (12), the production of these compounds from $\alpha$-MPT could result in effects independent of those due to inhibition of norepinephrine synthesis. Whereas this does not seem plausible off hand, it must be recalled that the formation of catechol metabolites of $\alpha$-MPT is presumably occurring only in central and peripheral sympathetic structures, i.e., at the sites of the norepinephrine-synthesizing enzyme machinery and of sympathetic drug actions. In patients with pheochromocytoma, there probably is some preferential metabolism in the tumor. Present data indicate a considerably greater amount of catechol drug metabolites in the urine during maintenance treatment than after a single dose. Thus, a possible contribution of catechol compounds to the pharmacological actions of $\alpha$-MPT must be considered. While some evidence against this possibility is offered in the second report (5), to settle this point fully it is important to study other tyrosine hydroxylase inhibitors, e.g., $\alpha$-methylphenylalanine (13), which are not metaholized significantly to catechols.

$\alpha$-MPT was fairly well absorbed from the gastrointestinal tract over a wide range of dosage as indicated by urinary excretion of $44-88 \%$ of the administered drug. The values may under- state the degree of absorption since no account was taken of possible extra-renal elimination. The lack of an intravenous preparation of the drug precluded a comparison of plasma levels after intravenous administration with those after oral dosing. Further the latter could be measured with confidence only after administration of $\alpha$-MPT $-{ }^{3} \mathrm{H}$; the concentrations of $\alpha$-MPT in plasma could be estimated by fluorescence assay only after subtraction of control values of plasma tyrosine, both of which were of the same order of magnitude. Use of an amino acid analyzer was not helpful in this regard due to inadequate column separation of $\alpha$-MPT from tyrosine.

If one assumes that the properties of tyrosine hydroxylase in human tissues are similar to those of purified beef adrenal tyrosine hydroxylase (13) and that plasma levels of $\alpha$-MPT and tyrosine are equivalent to tissue concentrations, it is possible to estimate the degree of inhibition of catecholamine biosynthesis which would be expected to occur in patients. From the affinity constants for $\alpha$-MPT $\left(K_{i}=1.7 \times 10^{-5} \mathrm{M}\right)$ and tyrosine $\left(K_{m}\right.$ $\left.=6.25 \times 10^{-5} \mathrm{M}\right)$ and the experimentally determined plasma levels of drug and substrate, equations describing competitive inhibition may be applied to human tissues just as has been done successfully in the case of guinea pig tissues (2). From the plasma levels observed in this study, it is estimated that average plasma levels of drug on the order of $15-20 \mu \mathrm{g} / \mathrm{ml}$ or $10^{-4} \mathrm{M}$ would occur during maintenance treatment with 500 $1000 \mathrm{mg}$ of $\alpha$-MPT every $6 \mathrm{hr}$. The average value for plasma tyrosine is about $10 \mu \mathrm{g} / \mathrm{ml}$ and for calculation may be taken as $5 \times 10^{-5} \mathrm{M}$. From the aforementioned $K_{i}$ and $K_{m}$ values for $\alpha$-MPT and tyrosine and their plasma concentrations, it is calculated that treatment of fasting patients with $2.0-4.0 \mathrm{~g}$ of $\alpha$-MPT/day should result in approximately $75 \%$ inhibition of tyrosine hydroxylase. This is the order of magnitude of the reduction in catecholamine biosynthesis actually observed at such dosages in man (3-5). It is of interest that even if one were to administer as much as 6-8 $\mathrm{g}$ of $\alpha-\mathrm{MPT} /$ day and raise plasma levels proportionally to $40 \mu \mathrm{g} / \mathrm{ml}\left(2 \times 10^{-4} \mathrm{M}\right)$ inhibition would be increased to only $87 \%$. Under normal conditions of therapy dietary sources of tyrosine would elevate tissue levels intermittently and further reduce the degree of inhibition. 
It is apparent, therefore, that for practical reasons the maximal inhibition of norepinephrine synthesis which can be attained with $\alpha$-MPT is of the order of $70-80 \%$. One must conclude that aside from answering the possible role of catechol metabolites in the clinical effects produced by $\alpha$-MPT in man there is little to be gained in testing the other known competitive inhibitors whose $K_{i}$ values are greater than those of $\alpha$-MPT (13). Though the halogenated analogues of tyrosine generally demonstrated $K_{i}$ values less than that for $\alpha$-MPT when tested in vitro, the most potent of these, 3-iodo-tyrosine $\left(K_{i}=3.9 \times 10^{-7} \mathrm{M}\right)$, was completely ineffective in reducing catecholamine synthesis in man (4). This lack of effectiveness was presumably due to rapid inactivation by tissue dehalogenases, but whether the brominated or chlorinated analogues of $\alpha$-MPT $\left(K_{i}\right.$ values approximately $2 \times 10^{-6} \mathrm{M}$ ) would prove more effective in vivo is yet to be determined. To attain a significantly greater degree of inhibition in vivo will require either competitive inhibitors with $K_{i}$ values considerably lower than that for $\alpha$-MPT or inhibitors which are noncompetitive with tyrosine.

\section{ACKNOWLEDGMENTS}

The authors state their appreciation of the excellent technical assistance rendered by Mrs. Diane Warren, Mrs. Katherine Gvozdas, and Mrs. Jane Bell.

\section{REFERENCES}

1. Spector, S., A. Sjoerdsma, and S. Udenfriend. 1965. Blockade of endogenous norepinephrine synthesis by $\alpha$-methyl-tyrosine, an inhibitor of tyrosine hydroxylase. J. Pharmacol. Exptl. Therap. 147: 86.
2. Udenfriend, S., P. Zaltzman-Nirenberg, R. Gordon, and S. Spector. 1966. Evaluation of the biochemical effects produced in vivo by inhibitors of the three enzymes involved in norepinephrine biosynthesis. Mol. Pharmacol. 2: 95.

3. Sjoerdsma, A., K. Engelman, S. Spector, and S. Udenfriend. 1965. Inhibition of catecholamine synthesis in man with alpha-methyl-tyrosine, an inhibitor of tyrosine hydroxylase. Lancet. 2: 1092.

4. Engelman, K., and A. Sjoerdsma. 1966. Inhibition of catecholamine biosynthesis in man. Circulation Res. 18 and 19(Suppl.): 1.

5. Engelman, K., D. Horwitz, E. Jequier, and A. Sjoerdsma. 1968. Biochemical and pharmacologic effects of $\alpha$-methyltyrosine in man. J. Clin. Invest. 47: 577.

6. Waalkes, T. P., and S. Udenfriend. 1957. A fluorimetric method for the estimation of tyrosine in plasma and tissue. J. Lab. Clin. Med. 50: 733.

7. Crout, J. R. 1961. Catecholamines in urine. In Standard Methods of Clinical Chemistry. D. Seligson, editor. Academic Press Inc., New York. 62.

8. von Euler, U. S., and I. Floding. 1956. Diagnosis of pheochromocytoma by fluorimetric estimation of adrenaline and noradrenaline in urine. Scand. J. Clin. Lab. Invest. 8: 288.

9. Roberts, M. 1962. A note on the use of cellulose phosphate cation-exchange paper for the separation of catecholamines, and some other biogenic amines. J. Pharm. Pharmacol. 14: 746.

10. Bray, G. A. 1960. A simple efficient liquid scintillator for counting aqueous solutions in a liquid scintillation counter. Anal. Biochem. 1: 279.

11. Sjoerdsma, A., A. Vendsalu, and K. Engelman. 1963. Studies on the metabolism and mechanism of action of methyldopa. Circulation. 28: 492.

12. Stone, C. A., and C. C. Porter. 1966. Methyldopa and adrenergic nerve function. Pharmacol. Rev. 18: 569.

13. Udenfriend, S., P. Zaltzman-Nirenberg, and $T$. Nagatsu. 1965. Inhibitors of purified beef adrenal tyrosine hydroxylase. Biochem. Pharmacol. 14: 837. 